\title{
RIGHT LUNG WITH DISTINCT LOBAR PATTERN: AN UNUSUAL VARIANT
}

\begin{tabular}{ll}
\hline Anatomy & \\
$\begin{array}{l}\text { Dr. Ankita } \\
\text { Chauhan* }\end{array}$ & $\begin{array}{l}\text { Junior Resident, Department of Anatomy, Dr. R.P.G.M.C., Kangra at Tanda, Himachal } \\
\text { Pradesh, India. }{ }^{*} \text { Corresponding Author }\end{array}$ \\
\hline Dr. Suman Yadav & $\begin{array}{l}\text { Professor and Head, Department of Anatomy, Dr. R.P.G.M.C., Kangra at Tanda, Himachal } \\
\text { Pradesh, India }\end{array}$ \\
\hline Dr Nitin Patiyal & $\begin{array}{l}\text { Junior Resident, Department of Pharmacology, Dr. R.P.G.M.C., Kangra at Tanda, } \\
\text { Himachal Pradesh, India }\end{array}$ \\
\hline
\end{tabular}

\section{ABSTRACT}

The lungs are paired, soft and spongy organs of respiration present in the greater part of thoracic cavity on either side of mediastinum resting on diaphragm. The right lung is typically divided into three lobes namely superior, middle and inferior by the oblique and horizontal fissures. The left lung is divided into superior and inferior lobes by a single deep oblique fissure. The fissures act as a plane of cleavage covered by extensions of pulmonary pleura that helps in expansion of lungs during respiration. During the routine dissection of thoracic region of human cadaver, right lung with accessory fissures and distinctive lobar pattern was observed. The right lung was divided into five disproportionate lobes by four fissures. The left lung had normal anatomy without any variation in this case. The variations in the fissures and lobar pattern of lungs are not uncommon and are due to altered developmental process during intrauterine life. The anatomical knowledge of these variations is important for clinicians prior to performing any pulmonary surgical procedures and to prevent postoperative complications.

\section{KEYWORDS}

Accessory Lobes, Fissures, Right lung, Unusual

\section{INTRODUCTION}

Human lungs are paired, soft and spongy organs of respiration present in the greater part of thoracic cavity on either side of mediastinum. The medial surface of each lung is attached to the mediastinum by a narrow root from where the bronchi, blood vessels, lymphatics and nerves enter or leave the lung.

The lungs are rich in elastic tissue that helps in expansion during respiration. Each principal bronchus divides into three lobar bronchi on the right and two on the left.

The right lung being shorter and broader is usually divided into three lobes namely superior, middle and inferior by the oblique and horizontal fissures. The oblique fissure begins posteriorly at the level of fifth thoracic vertebra about $6.5 \mathrm{~cm}$ below the apex and then taking a spiral course antero-inferiorly to meet the inferior margin at sixth costochondral junction. The oblique fissure separates the inferior lobe from superior and middle lobes in the right lung. The small triangular middle lobe is separated from the superior lobe by a small horizontal fissure beginning at the level of fourth costal cartilage from anterior border of lung extending horizontally backwards to meet the oblique fissure in the mid- axillary line. The left lung is divided into superior and inferior lobes by a single deep oblique fissure which is usually more vertical as compared to right lung.

The fissures act as a plane of cleavage covered by extensions of pulmonary pleura that helps in movement of lobes of lungs separately and also over each other during inspiration. ${ }^{4}$

The anatomical knowledge of incomplete separation of lobes and presence of accessory or incomplete fissures is important prior to performing any pulmonary surgical procedures and also in radiology as these can be misinterpreted on chest radiographs and computed tomography scans.

\section{CASE:}

During routine dissection of thoracic region of adult male cadaver in accordance with ethical standards at the department of anatomy at Dr. R.P.G.M.C., Kangra at Tanda, it was noticed that the right lung had variant accessory fissures and lobes.

The right lung was divided into five distinct lobes by four fissures. The oblique fissure (A) was lying more vertically, beginning from the posterior border about $4 \mathrm{~cm}$ below the apex thus dividing the right lung into superior and inferior lobes. One horizontal fissure (B) was seen starting from the posterior margin of lung and coursing anteriorly to meet the oblique fissure creating an accessory lobe. This lobe corresponds to the inferior superior bronchopulmonary segment separated from anterior basal and lateral basal segments of inferior lobe. Another small oblique fissure (C) was seen in place of classical horizontal fissure leading to formation of middle lobe. One incomplete transverse fissure (D) was seen in middle lobe region dividing it into partial segments.

The mediastinal surface and hilar region of right lung had normal morphological features.

The left lung was having one oblique fissure and two lobes with no variation in its anatomy.

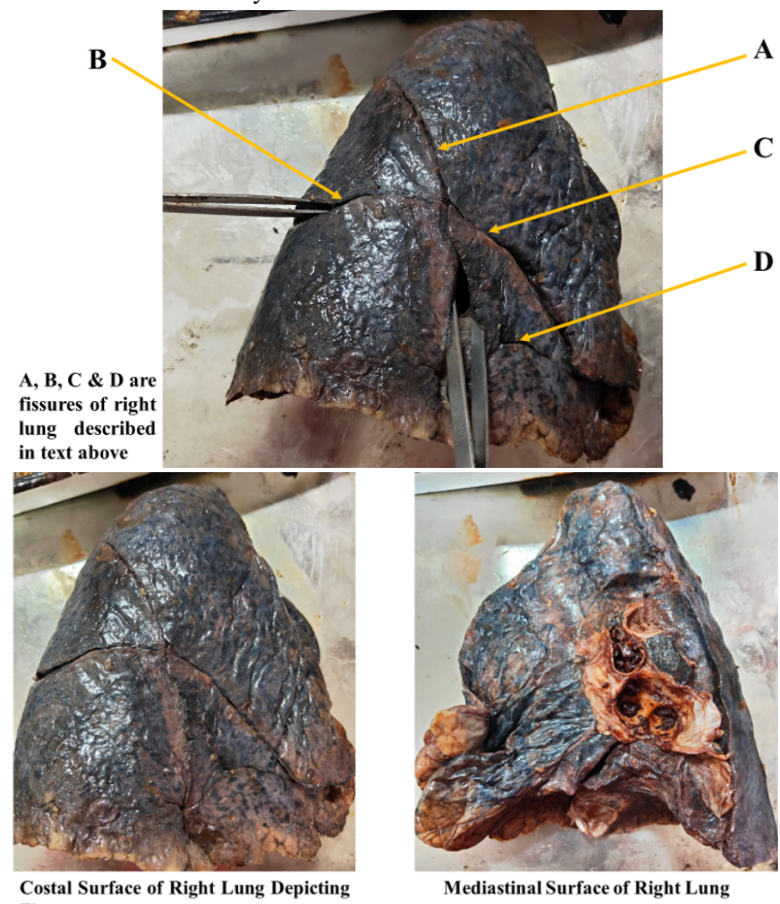

Fissures

\section{DISCUSSION}

Developmentally the lung bud arises as a ventral outgrowth from the wall of foregut around $4^{\text {th }}$ week of gestation. The epithelial lining is thus completely endodermal in origin whereas the connective components are derived from splanchnic mesoderm. The lung bud splits into right and left primary bronchial buds that correspond to the 
development of right and left lung respectively. During $5^{\text {th }}$ week, these primary buds yield three secondary bronchial buds on the right side and two on the left. These secondary bronchial buds will eventually give rise to three lobes in the right lung and two lobes in the left lung. Further extensive branching of bronchial buds will form numerous bronchopulmonary segments which fuse later except at the site of formation of horizontal and oblique fissures. ${ }^{5,6}$

Defective obliteration of these fissures either completely or incompletely during development results in structural variations in the lungs.

In a case reported by Godfrey et al, complete variant fissure and three incomplete fissures in right lung was observed along with one variant transverse fissure in left lung giving different bronchopulmonary segments pattern. ${ }^{8}$

George et al studied morphology of the human lungs in Indian cadavers and observed similar variations in the fissures and lobes of lungs.

A study conducted by Ughade et al on 100 lung specimens reported accessory fissures and lobes in 14 right lung specimens and in 8 left lung specimens. ${ }^{10}$

\section{CONCLUSION}

The variations in the fissures such as presence of accessory fissures or absent horizontal fissure are normal and attributed to altered pulmonary development in fetal life. In our case, the presence of accessory fissures which lead to formation of accessory lobes in right lung was observed. This is atypical variant seen in right lung and may be misinterpreted on chest radiographs as lung lesion. Better understanding of these anatomical variations of lungs along with their fissures and lobes is important for surgeons to minimise postoperative complications like air leakage following lobectomies.

\section{REFERENCES:}

. Muresian H. Lungs and diaphragm. In; Stringer MD, Standring S, editors. Gray's anatomy: the anatomical basis of clinical practice. $41^{\text {st }}$ ed. London: Elsevier; 2016. p. 957-8

2. The thorax. In; Romanes GJ, editor. Cunningham's Manual of practical anatomy. Thorax and abdomen. $15^{\text {th }}$ ed. Oxford university press; 2010 . p. 30-4

3. Snell RS. Clinical anatomy by regions. Wolters Kluwer (India);2018. p. 78-9

4. The lungs. In; Dutta AK. Essentials of human anatomy (Thorax and Abdomen). $10^{\text {th }} \mathrm{ed}$. Current books international: India; 2018.p. 32-7

5. Respiratory system. In; Sadler TW editor. Langman's medical embryology. 12th ed: Respiratory system. In; Sadler TW ed
Wolters Kluwer(India);2019. p. 229-33

6. Development of the Respiratory System and Body Cavities. In; Schoenwolf GC, Bleyl SB, Brauer PR, Francis-West PH. Larsen's human embryology. $5^{\text {th }}$ ed. Philadelphia: Elsevier; 2015. p. 252-5

7. Meenakshi S, Manjunath KY, Balasubramanyam V. Morphological variations of the lung fissures and lobes. Indian J Chest Dis and Allied Sci. $2004 \mathrm{Jul} ; 46: 179-82$.

8. Esomonu UG, Taura MG, Modibbo MH, Egwu AO. Variation in the lobar pattern of the right and left lungs: A case report. AMJ 2013;6(10):511-514

9. George BM, Nayak SB, Marpalli S. Morphological variations of the lungs: a study conducted on Indian cadavers. Anatomy \& cell biology. 2014 Dec 1;47(4):253-8.

10. Ughade JM, Kardile PB, Tekade PR. VARIATION IN LOBES AND FISSURES OF LUNG. Int J Anat Res. 2018;6(1.3):4973-80 